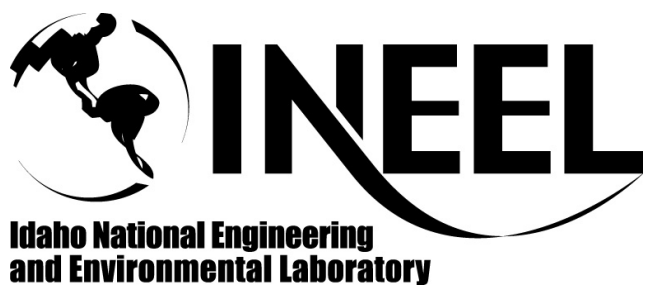

\title{
JUPITER-II Molten Salt Flibe Research: An Update on Tritium, Mobilization and Redox Chemistry Experiments
}

\author{
David A. Petti \\ G.R. Smolik \\ Michael F.Simpson \\ John P. Sharpe \\ R.A. Anderl \\ S. Fukada \\ Y. Hatano \\ M. Hara \\ Y. Oya \\ T. Terai \\ D.-K. Sze \\ S. Tanaka
}

May 2005

\section{International Symposium on Fusion Nuclear Technology}

This is a preprint of a paper intended for publication in a journal or proceedings. Since changes may be made before publication, this preprint should not be cited or reproduced without permission of the author.

This document was prepared as an account of work sponsored by an agency of the United States Government. Neither the United States Government nor any agency thereof, or any of their employees, makes any warranty, expressed or implied, or assumes any legal liability or responsibility for any third party's use, or the results of such use, of any information, apparatus, product or process disclosed in this report, or represents that its use by such third party would not infringe privately owned rights. The views expressed in this paper are not necessarily those of the U.S. Government or the sponsoring agency. 


\title{
JUPITER-II molten salt Flibe research: An update on tritium, mobilization and redox chemistry experiments
}

\author{
David A. Petti ${ }^{\mathrm{a}, *}$, G.R. Smolik ${ }^{\mathrm{a}}$, Michael F. Simpson ${ }^{\mathrm{a}}$, \\ John P. Sharpe ${ }^{\text {a }}$, R.A. Anderl ${ }^{a}$, S. Fukada ${ }^{b}$, Y. Hatano ${ }^{c}$, M. Hara ${ }^{\text {, }}$, \\ Y. Oya ${ }^{d}$, T. Terai ${ }^{d}$, D.-K. Sze ${ }^{\text {e }}$, S. Tanaka ${ }^{d}$ \\ a Fusion Safety Program Idaho National Laboratory, P.O. Box 1625, Idaho Falls, ID 83415, USA \\ ${ }^{\mathrm{b}}$ Kyushu University, Hakozaki, Higashi-ku, Fukuoka 812-8581, Japan \\ ${ }^{c}$ Hydrogen Isotope Research Center, Toyama University, Gofuku 3190, Toyama 930-8555, Japan \\ ${ }^{\mathrm{d}}$ University of Tokyo, Hongo, Bunkyo-ku, Tokyo 113-8656, Japan \\ ' University of California at San Diego, La Jolla, CA 92093-0427, USA
}

\begin{abstract}
The second Japan/US Program on Irradiation Tests for Fusion Research (JUPITER-II) began on April 1, 2001. Part of the collaborative research centers on studies of the molten salt $2 \mathrm{LiF}_{2}-\mathrm{BeF}_{2}$ (also known as Flibe) for fusion applications. Flibe has been proposed as a self-cooled breeder in both magnetic and inertial fusion power plant designs over the last 25 years. The key feasibility issues associated with the use of Flibe are the corrosion of structural material by the molten salt, tritium behavior and control in the molten salt blanket system, and safe handling practices and releases from Flibe during an accidental spill. These issues are all being addressed under the JUPITER-II program at the Idaho National Laboratory in the Safety and Tritium Applied Research (STAR) facility. In this paper, we review the program to date in the area of tritium/deuterium behavior, Flibe mobilization under accident conditions and testing of $\mathrm{Be}$ as a redox agent to control corrosion. Future activities planned through the end of the collaboration are also presented.
\end{abstract}

* Corresponding author. Tel.: +1 2085267735 ; fax: +12085262930 .

E-mail address: pti@inel.gov (D.A. Petti).

\section{Background and objectives}

A key issue associated with the use of the molten salt, Flibe $\left(\mathrm{Li}_{2} \mathrm{BeF}_{4}\right)$, in fusion applications is the control of tritium permeation and structural material corrosion in the blanket. Irradiation of Flibe will pro- 
duce in-situ tritium and free (or excess) fluorine ions via numerous nuclear reactions. This free fluorine can impact corrosion processes. The fluorine ions can either combine with the triton produced to form TF, combine with other metal impurities in the Flibe, or remain as a fluorine ion. These can react with the structural metal, depending on the kinetics of the competing reactions. The tritium can also permeate through the structural material of the coolant system with eventual release to the environment.

Thermodynamic stability of the fluoride salt components is quite important because molten salt corrosion is usually induced by reduction/oxidation (redox) reactions. Corrosion control is best accomplished by control of the free fluorine in the system, usually by a redox agent via the reaction:

$x \mathrm{M}+\mathrm{F}_{2}=x \mathrm{MF}_{2 / x}$

where $\mathrm{M}$ is the redox agent. The redox agent if properly selected would tie up all of the free fluorine generated on each coolant pass in the system and thus prevent it from being available for reaction with the metals in the structural components. The fluoride chemical potential is defined as $-R T \ln p_{\mathrm{F}_{2}}$ and is plotted for a number of different fluoride reactions in Fig. 1. The more negative the fluoride chemical potential the better that redox agent is at controlling free fluorine generated in the system. Based on these results, we have selected $\mathrm{Be}$ as the redox agent for our studies. Be has been previ-

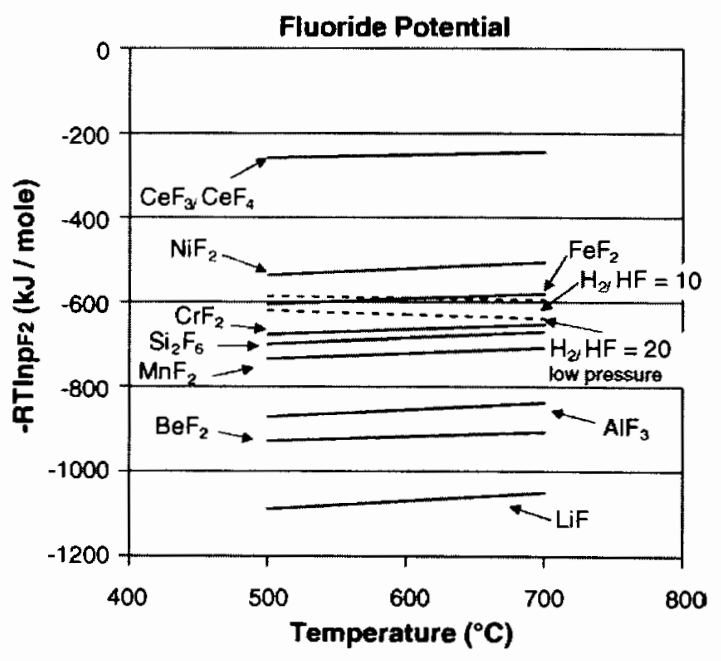

Fig. 1. Fluoride potential for different materials. ously proposed as a redox agent for fusion applications such as HYLIFE-II [1]. It is probably the most natural choice of a redox agent in the fusion context since $\mathrm{Be}$ is needed for neutron multiplication in a magnetic fusion blanket to ensure adequate tritium breeding [2]. Other agents $\left(\mathrm{Ce}, \mathrm{Eu}, \mathrm{HF} / \mathrm{H}_{2}\right)$ do not have a low enough fluoride potential to suppress TF formation to a level where corrosion is not a concern.

The overall tritium behavior in the system will be a function of the REDOX control strategy that is adopted. The low solubility of tritium in Flibe and the strongly reducing conditions expected in a REDOX-controlled Flibe fusion blanket would suggest that tritium would be present primarily as $T_{2}(\mathrm{~g})$. The behavior of tritium with structural materials of interest in a REDOX-controlled Flibe fusion blanket needs to be understood.

Of equal importance are the safety issues associated with the handling of the Flibe and its use as a coolant in a fusion power plant [3]. With the recent tightening of Be standards in the US [4], there is continued attention to the use of all Be containing compounds. There is a need to know the physio-chemical forms of vapors and aerosols produced in a spill of Flibe when it interacts with air or water. Although unirradiated Flibe is not significantly chemically reactive with air or steam, reaction with moist air or water is expected to produce $\mathrm{HF}$ and could mobilize tritium, ${ }^{18} \mathrm{~F}$ and other radionuclides produced during irradiation.

Based on the key issues associated with the use of Flibe as a coolant in a fusion blanket, the objectives of our work are:

- to develop the capability to purify Flibe at the liter scale for use in the experiments;

- to characterize tritium/deuterium behavior (e.g., solubility and diffusivity) in REDOX-controlled and non-REDOX controlled Flibe;

- to characterize the magnitude and physio-chemical forms of material mobilized during an accidental spill of Flibe and to develop corresponding safe handling practices;

- to develop a redox agent for use in Flibe in a fusion blanket;

- to demonstrate the effectiveness of the redox agent in terms of structural material corrosion for fusion materials of interest using a simple dip specimens in small scale pot type experiments. 


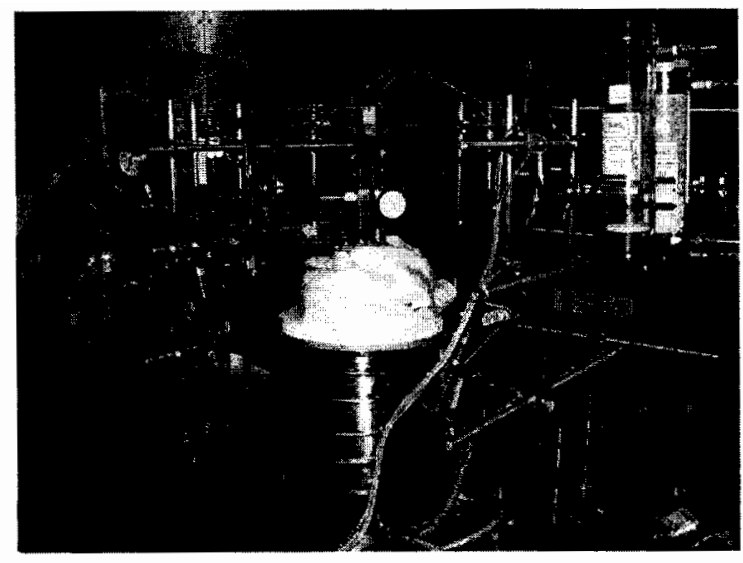

Fig. 2. Photograph of Flibe purification setup.

\section{Flibe purification, sampling and analysis}

The Flibe used in the JUPITER-II collaboration was prepared from reagent grade chemicals. Both the $\mathrm{Be}_{2} \mathrm{~F}$ and $\mathrm{LiF}$ were listed as $99.9 \%$ pure based upon the metals content. Oxygen, nitrogen and carbon were determined by methods utilizing LECO $^{\circledR}$ equipment.

Metals analyses were by inductively coupled plasma-atomic emission spectroscopy (ICP-AES) and mass spectrometry (ICP-MS). The powders were dried and weighed to provide the mole ratio of 2:1 and then purged with helium and melted. The salt was then purged with gas mixtures of $\mathrm{He}, \mathrm{H}_{2}$ and $\mathrm{HF}$ at $520^{\circ} \mathrm{C}$ to reduce inherent oxides in a pot (see Fig. 2).

The salt was then filtered through a $60-\mu \mathrm{m}$ metal mesh frit during a transfer to another vessel. The impurities in the final product are given in Table 1. Measurements of beryllium and lithium in the final product ranged from 8.3 to 8.5 and 13.06 to $13.2 \mathrm{wt} \%$, respectively. Although these are lower than the theoretical values of 9.04 and $14.14 \mathrm{wt} \%$, the lithium to beryllium mole ratios of 2.01-2.06 are close to the targeted composition. This suggests that the weight-based dis- crepancies might be due to absorbed water or analytical biases.

\section{Deuterium/tritium behavior}

Tritium behavior in molten salts depends strongly on the tritium chemical species in the salt and on the diffusive and solution properties of those species [5]. Several experiments that focused on characterization of tritium species in Flibe under neutron exposure [6-10] indicate that the tritium was borne as $\mathrm{T}^{+}$and most likely was bonded to $\mathrm{F}^{-}$in the salt as TF, unless there was an abundance of hydrogen in solution. Use of hydrogen in purge gas streams over and through the molten salt increased the hydrogen in solution, promoted changes in the tritium chemical species to HT via exchange reactions, enhanced release of tritium from the salt to the gas phase above the salt, and enhanced tritium permeation through metal walls surrounding the molten salt. Only a few studies reported transport properties (diffusivity and solubility). Diffusion coefficients $\left(500-800^{\circ} \mathrm{C}\right)$ were derived in experiments based on $\mathrm{T}^{+}$diffusion from a capillary containing irradiated Flibe into a reservoir containing molten Flibe [11]. Tritium diffusion as $\mathrm{T}^{+}$ was also measured in solid Flibe at temperatures from 350 to $400^{\circ} \mathrm{C}$ [12]. Solubility measurements, made for $\mathrm{H}_{2}, \mathrm{D}_{2}, \mathrm{HF}$ and DF in Flibe at $500-700^{\circ} \mathrm{C}$, indicated that the solubility of $\mathrm{H}_{2}$ and $\mathrm{D}_{2}$ was about a factor of 100 less than that for $\mathrm{HF}$ and $\mathrm{DF}$ at $600^{\circ} \mathrm{C}[13,14]$.

As part of the JUPITER-II program, deuterium transport experiments were conducted in a cylindrically symmetric, dual probe permeation pot setup illustrated in Fig. 3 [15]. The assembly consisted of a type-316 stainless-steel pot, a nickel crucible for containing Flibe, two permeation probes of thin-walled nickel, a gas-manifold to enable Ar purge gas flow through assembly volumes, and a quadrupole mass spectrometer (QMS) for on-line measurements of the flow stream gas compositions. Each probe was equipped with barrier volumes at the top to minimize direct deuterium

Table 1

Impurities in ingredients and final salt

\begin{tabular}{lcccccr}
\hline & $\mathrm{O}(\mathrm{ppm})$ & $\mathrm{C}(\mathrm{ppm})$ & $\mathrm{N}(\mathrm{ppm})$ & $\mathrm{Fe}(\mathrm{ppm})$ & $\mathrm{Ni}(\mathrm{ppm})$ & $\mathrm{Cr}(\mathrm{ppm})$ \\
\hline $\mathrm{BeF}_{2}$ & 5700 & $<20$ & 58 & 295 & 20 & 18 \\
$\mathrm{LiF}$ & 60 & $<20$ & 78 & 100 & 30 & 4 \\
Flibe & 560 & 10 & 32 & 260 & 15 & 16 \\
\hline
\end{tabular}




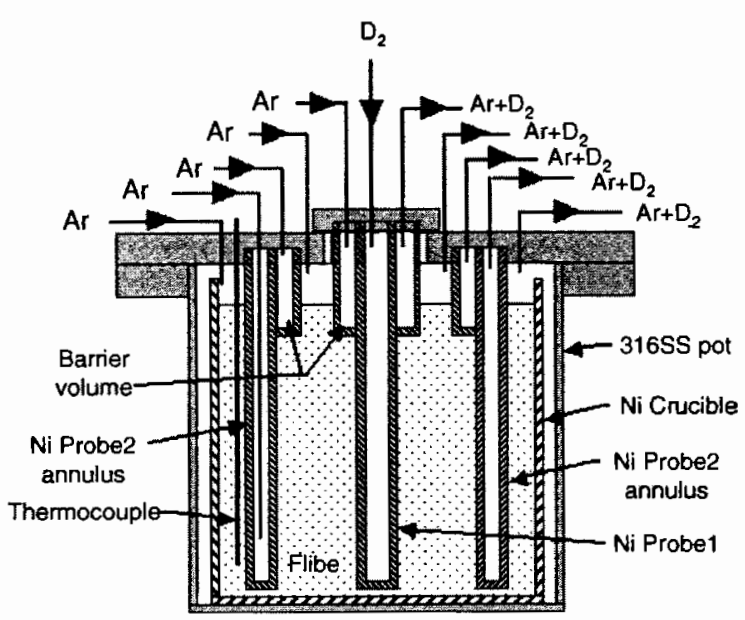

Fig. 3. Schematic illustration of cylindrically symmetric, permeation probe assembly. Overall dimensions of the steel pot were: $178-\mathrm{mm}$ height and a 102-mm o.d. pot wall that was $3-\mathrm{mm}$ thick. Nickel crucible dimensions were: $91.4-\mathrm{mm}$ o.d., $85-\mathrm{mm}$ i.d. and $150-\mathrm{mm}$ height. Probe- 2 was a cylindrical annulus with $75-\mathrm{mm}$ o.d., $51-\mathrm{mm}$ i.d., $0.5-\mathrm{mm}$ wall, and $110-\mathrm{mm}$ height. Probe-1 was a $12-\mathrm{mm}$ o.d. cylinder with $0.5-\mathrm{mm}$ wall and a $110-\mathrm{mm}$ height.

transport between the probes and the cover gas above the molten salt. Typically, with the pot at test temperature, probe-1 was pressurized with deuterium and QMS analysis of $\mathrm{Ar}$ gas from probe-2 provided a measure of the deuterium that permeated through the walls of probe-1, the molten Flibe and the walls of probe-2. The barrier volumes and the volumes above the salt were purged with separate Ar gas streams that were analyzed sequentially with the QMS.

Several deuterium permeation experiments were made with the system at temperatures of 600 and $650^{\circ} \mathrm{C}$ and with a deuterium pressure of around $9.0 \times 10^{4} \mathrm{~Pa}$ in probe-1. Fig. 4 compares the results of deuterium permeation experiments at $600^{\circ} \mathrm{C}$ with no Flibe in the system (Exp A) and with Flibe filling the assembly (Exp B). Probe- 2 Ar flow rates were $25 \mathrm{~cm}^{3} / \mathrm{min}$ for both experiments. For Exp A, measured $\mathrm{D}_{2}$ partial pressures in probe-2 (dash-dot line) are plotted relative to the left axis. The Exp A deuterium transient behavior reflects the condition with no Ar flow through the volume between the probes and the case when the flow through the inter-probe volume was changed to $100 \mathrm{~cm}^{3} / \mathrm{min}$. The temporal deuterium behavior followed a traditional permeation transient, and derived permeability coefficients agreed with pre-

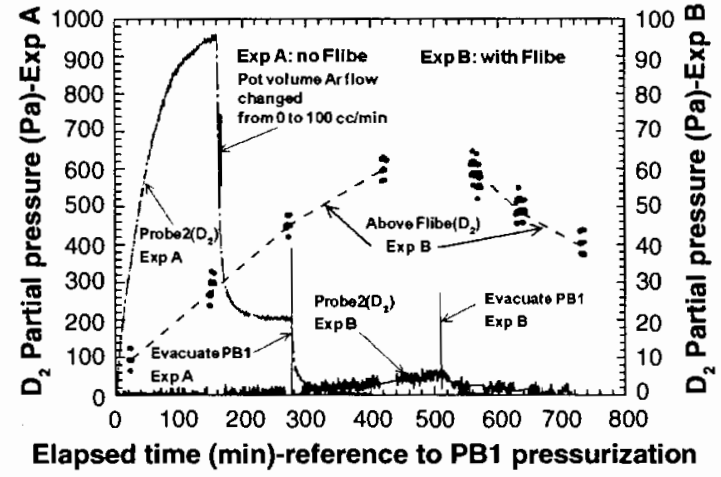

Fig. 4. Comparison of measured deuterium transport data for experiments at $600^{\circ} \mathrm{C}$ with $(\operatorname{Exp} B)$ and without Flibe $(\operatorname{Exp} \mathrm{A})$.

vious work $[16,17]$. For $\operatorname{Exp} B$, measured $\mathrm{D}_{2}$ partial pressure data (plotted on the right ordinate) are shown for probe-2 (solid line) and above the Flibe (dash line). Because the QMS was alternately switched to analyze flow streams through probe- 2 and above the Flibe, the plotted data show regions with no scatter. Two features of the Exp B data reflect the influence of Flibe on permeation. First, there is significant time delay (on the order of 300 minutes) in the probe- $2 \mathrm{D}_{2}$ permeation signal and in the buildup of deuterium above the Flibe. Second, the maximum $D_{2}$ partial pressures in probe- 2 and above the salt are a factor of 200 and 20 less than the partial pressure in probe- 2 observed in Exp A. These results are due to the low solubility and low diffusivity of $\mathrm{D}_{2}$ in Flibe.

TMAP-4 simulation calculations were used to evaluate the overall deuterium permeation rates in the Flibe/Ni/ $\mathrm{D}_{2}$ system using previous literature transport data for these materials. These analyses showed that diffusion in Flibe was rate-determining for our experimental conditions. Results of the analytical fit (by adjustment of diffusivity and solubility values) were compared to experimental data measured at 600 and $650^{\circ} \mathrm{C}$.

Diffusion coefficients derived from these experiments are compared to previously published data in Fig. 5. Our diffusion results are about a factor of 2-5 less than those reported by Oishi et al. [11] for $\mathrm{T}^{+}$transport in molten Flibe, suggesting that deuterium was also diffusing as the $\mathrm{D}^{+}$species in our experiments. Both of these results are about a factor of 2-5 greater than those derived from the viscosity using the Stokes-Einstein relation, $D=k T /(6 \pi R \eta)$, assuming a particle radius, $R$, 


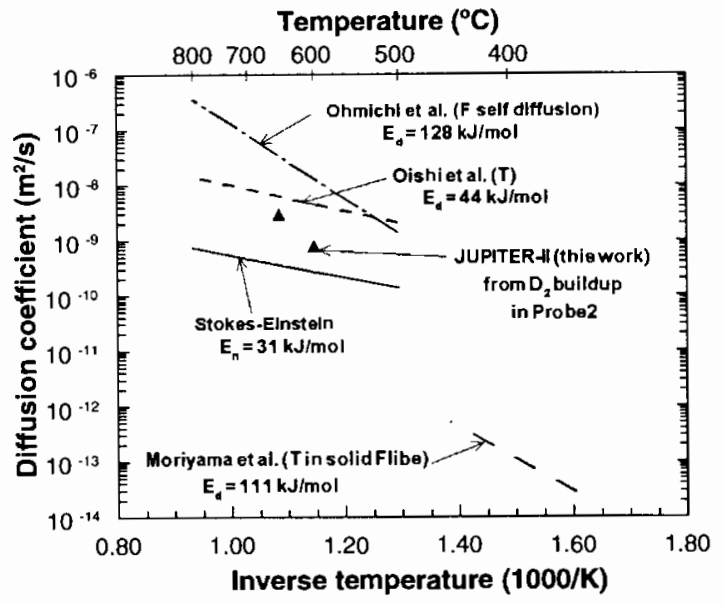

Fig. 5. Diffusion coefficients for Flibe.

of $2 \AA$ and the viscosity of Flibe, $\eta$, reported by Cantor [18] for $2 \mathrm{LiF} \cdot \mathrm{BeF}_{2}$. The diffusion activation energy for the Oishi et al. data is consistent with the viscosity data. However, a two-point fit to our diffusion coefficients (a dangerous approach with such limited data) yields a diffusion activation energy comparable to that for $\mathrm{F}^{-}$self diffusion. Such a result would suggest transport mechanisms similar to that postulated by Ohmichi et al. [19], namely ion-pair diffusion or exchange processes that break $\mathrm{Be}-\mathrm{F}$ bonds.

Solubility coefficients derived from these experiments were comparable to those for DF in Flibe, as reported by Field and Shaffer [14], rather than to those for $\mathrm{H}_{2}, \mathrm{D}_{2}$, reported by Malinauskas et al. [13]. These results suggest that the chemical potential of deuterium in the Flibe for the current experiments was greater than the chemical potential of $\mathrm{D}$ solute when the dominant species of deuterium in Flibe was $D_{2}$. This interpretation is consistent with previous experiments in which a significant overpressure of hydrogen was required to promote exchange reactions with $\mathrm{TF}$ in the salt and facilitate transport of tritium in the Flibe as HT.

Thus, these results suggest that deuterium transport in the present experiments was mediated by the presence of a bond between $\mathrm{D}^{+}$and $\mathrm{F}^{-}$in the molten salt. This could be due to the presence of excess residual $\mathrm{HF}$ or free fluorine in the salt following the hydro-fluorination purification process, to ion-pair diffusion processes suggested by Ohmichi et al. [19], or to insufficient concentrations of deuterium in the salt.
Future experiments will examine the solubility of tritium in Flibe at different partial pressures and different REDOX conditions.

\section{Flibe mobilization}

A key safety issue associated with Flibe is the mobilization of vapors and aerosols from accidental introduction of air, moist air, or steam to the molten salt. Mobilization tests were performed with argon, air and moist air using a classical transpiration apparatus designed for vapor pressure determinations [20]. Whereas previous vapor pressures determined by Oak Ridge National Laboratory (ORNL) studies were conducted at temperatures of above $1000^{\circ} \mathrm{C}$ [21], current applications of this salt in fusion energy devices are around $600^{\circ} \mathrm{C}$. Recent models $[22,23]$ have been developed to express vapor pressures for temperatures more applicable to fusion energy applications. Olander et al. [22] compared the extrapolation of ORNL data with a model utilizing selected activity coefficients from various studies and prominent vapor species as identified by mass spectroscopy by Büchler and Stauffer [24]. The latter authors reported $\mathrm{BeF}_{2}$ and $\mathrm{LiBeF}_{3}$ as the dominant vapor species above the $\mathrm{LiF}-\mathrm{BeF}_{2}$ system. Above a $\mathrm{LiF}$ saturated solution of $74 \% \mathrm{LiF}-26 \% \mathrm{BeF}_{2}$ at $600{ }^{\circ} \mathrm{C}$ these two species were found to exist in a ratio of $10: 1$. The two models $[22,23]$ provide essentially the same pressure for $\mathrm{BeF}_{2}$ that is about $60 \%$ below the extrapolated ORNL data. The models differ only by the minor contribution attributed to lithium bearing species. Our study for JUPITER-II was undertaken to provide experimental confirmation of vapor pressures at the lower fusion-relevant temperatures and to determine influences of different environments, e.g., argon, dry air and moist air or steam possibly encountered during an accident. Another goal was to obtain mass flux measurements from conditions approximating saturation to provide a basis for comparison with loss of vacuum safety studies addressing blanket design concepts for APEX [25].

Mobilization tests of the salt were performed in a transpiration setup similar to that described by Sense et al. [26] for vapor pressure measurements. A schematic of the test system setup in an inert gas glove box is shown in Fig. 6. The test chamber contained a nickel pipe, $2.09 \mathrm{~cm}$ i.d. and $51 \mathrm{~cm}$ long, that was heated in 


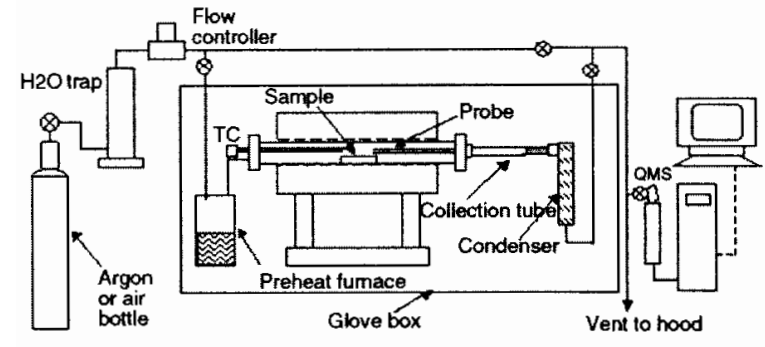

Fig. 6. Transpiration test setup.

a $36 \mathrm{~cm}$ long resistance heated muffle furnace. Flibe samples were contained at the center of the hot zone in different types of crucibles depending on the test environment. An Inconel 600 tube was used as a probe through which vapors were transported by the gas flow. A steep thermal gradient existed between the test region and the ends of the furnace, which forced condensation/deposition of mobilized material onto surfaces of the probe and/or in packed quartz wool attached to the tubing. Tests were performed in argon, dry air and moist air (air saturated with water vapor at $40^{\circ} \mathrm{C}$ ).

Flibe salt was tested in argon at temperatures of $500,600,700$ and $800^{\circ} \mathrm{C}$ at flow rates of 25,50 and $100 \mathrm{sccm}$. Nickel crucibles were used for most tests; however, some tests were also run in glassy carbon crucibles. Tests with dry air were run at these four temperatures with flow rates of 25 and $50 \mathrm{sccm}$. Tests in moist air were run at 600,700 and $800^{\circ} \mathrm{C}$ with flow rates of 25 and $50 \mathrm{sccm}$

The $\mathrm{BeF}_{2}$ and $\mathrm{LiBeF}_{3}$ partial pressures that were derived from the mobilized material chemical analyses for the argon tests are plotted in Fig. 7 along with those from the previous studies and models $[21,22,24]$. The

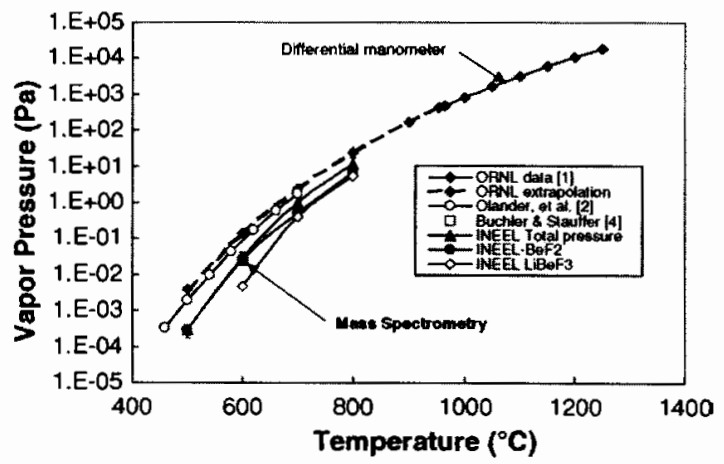

Fig. 7. Total pressure over Flibe.

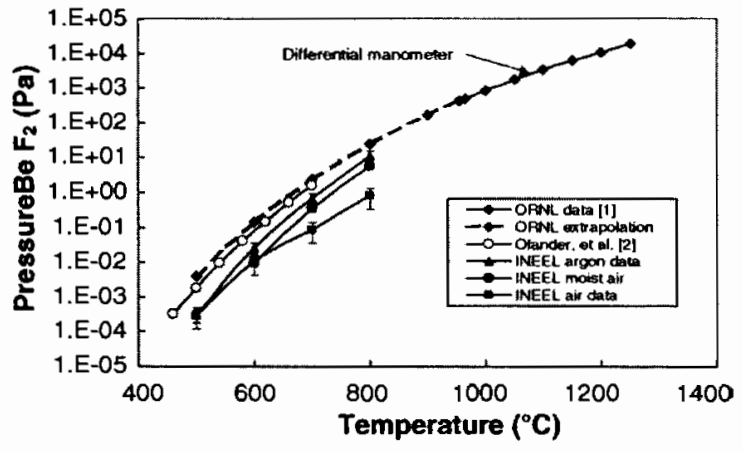

Fig. 8. $\mathrm{BeF}_{2}$ pressure in various environments.

plot shows the excellent agreement at $600^{\circ} \mathrm{C}$ of this study with that of Büchler and Stauffer [24]. The total pressures represented by Olander et al. [22], which are essentially equivalent to those of Zaghloul et al. [23], are about $60 \%$ lower than the extrapolated ORNL data [21]. Total measured pressures for $\mathrm{BeF}_{2}$ and $\mathrm{LiBeF}_{3}$ are two to three times lower than predicted values. The increasing contribution from the lithium species in the INEEL data is apparent at 700 and $800^{\circ} \mathrm{C}$.

Partial pressures calculated for $\mathrm{BeF}_{2}$ for all three test gases are shown in Fig. 8. The data for moist air parallels and are about one-half of those measured for the argon tests. The reason for the lower datum points in the dry air tests at 700 and $800^{\circ} \mathrm{C}$ is not known. This trend is based upon limited tests and some repeated tests would be needed to confirm this trend. The data did not show any markedly different volatilization rates in dry and moist air compared to those in argon.

Vapor pressures calculated for lithium bearing species, assuming one lithium atom per molecule, are plotted for the various test gases in Fig. 9. No differ-

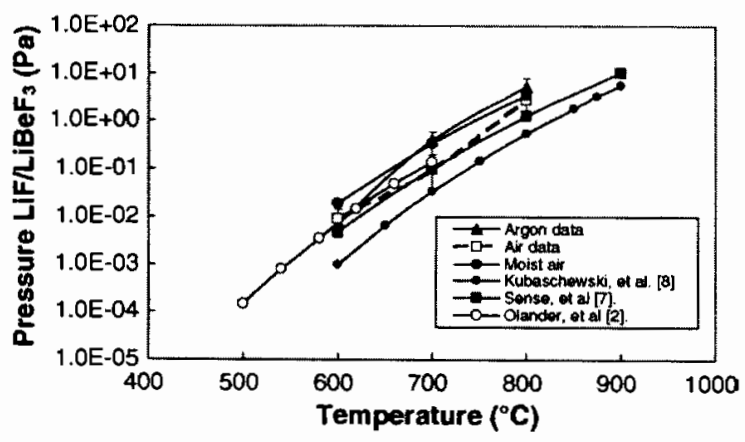

Fig. 9. Pressure of Li bearing vapor over Flibe. 
ences in the results can be seen between the environments considering the scatter within the data. The data are slightly higher than pressure of $\mathrm{LiBeF}_{3}$ indicated by Olander et al. [22] and that based on an extrapolation of the LiF data by Sense et al. [26] multiplied by 0.66 the mole fraction in Flibe to simulate ideal solution behavior. The latter extrapolation was from above the $845^{\circ} \mathrm{C}$ melting point of LiF.

Mass comparisons using probe interior ICP-AES measurements and sample loss for the argon test series in the nickel crucibles showed that about $22 \%$ of the material was deposited in the probe. The remainder was deposited on the probe exterior and the walls of the test chamber. This reflects the diffusion and re-deposition of material down the temperature gradient. Mass flux calculation $\left(\mathrm{kg} / \mathrm{m}^{2} \mathrm{~h}\right)$ obtained by adjusting ICP-AES measurements for the $22 \%$ factor generally agreed within a factor of two of the mass based determinations for individual tests. The model for safety assessments [25] assumes that in a spill of Flibe, the evaporation process from the surface becomes rate limiting by diffusion through the boundary layer. The boundary layer mass transport coefficient $K_{\mathrm{m}}$ of $0.01-0.03 \mathrm{~m} / \mathrm{s}$ derived for Flibe from this study was applied along with measured vapor pressures and mass based flux determinations to show that the vapor pressures for the argon tests were likely within $70 \%$ of saturation. This is in line with the comparison made with vapor pressures from the LiF study by Sense et al. [26]. Although the flow conditions within the test system are not specifically representative to the relatively placid conditions for a LOVA accident [25], the mass based flux values of $2.6 \times 10^{-2} \mathrm{~g} / \mathrm{m}^{2} \mathrm{~h}$ at $500^{\circ} \mathrm{C}, 7.7 \times 10^{-2} \mathrm{~g} / \mathrm{m}^{2} \mathrm{~h}$ at $600^{\circ} \mathrm{C}, 3.1 \times 10^{-1} \mathrm{~g} / \mathrm{m}^{2} \mathrm{~h}$ at $700^{\circ} \mathrm{C}$ and $2.4 \mathrm{~g} / \mathrm{m}^{2} \mathrm{~h}$ at $800^{\circ} \mathrm{C}$ could be used as first order approximations of evaporation rates.

\section{REDOX control}

A series of experiments was performed in which $\mathrm{HF}$ was bubbled through Flibe with varying concentrations of dissolved $\mathrm{Be}$ to investigate the viability of using $\mathrm{Be}$ as a redox agent in a molten Flibe $\left(2 \mathrm{LiF}-\mathrm{BeF}_{2}\right)$ blanket. Although some previous work has been reported that indicates $\mathrm{Be}$ is capable of serving as a redox agent and keeping the TF concentrations low [27], no quantitative measurement of the rate of the $\mathrm{Be}-\mathrm{TF}$ redox reaction is

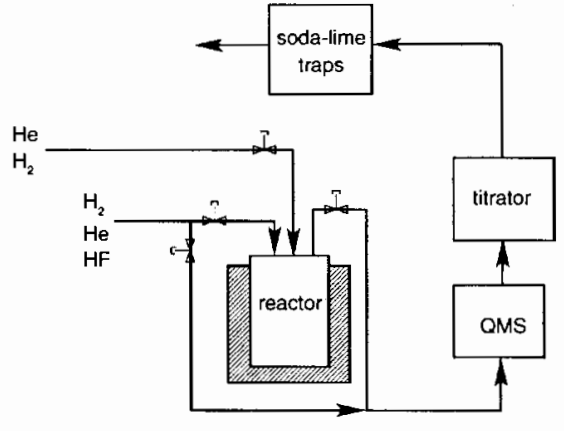

Fig. 10. Test system for measuring redox kinetics.

known to have been made. The objective of this work in the JUPITER-II collaboration was to perform such measurements with the goal of obtaining useful kinetic data that could be used to quantitatively validate the feasibility of using $\mathrm{Be}$ as a redox agent in Flibe. Of particular interest is whether the inclusion of $\mathrm{Be}$ in the salt can keep the TF concentrations below a level which would lead to structural materials corrosion.

A simplified diagram of the system used for observing the $\mathrm{HF}-\mathrm{Be}$ redox reaction is shown in Fig. 10. A mixture of $\mathrm{H}_{2}, \mathrm{He}$ and $\mathrm{HF}$ gases was introduced into the test reactor, while the effluent passed through a quadrupole mass spectrometer (QMS) followed by an autotitrator. Our initial experiments used $\mathrm{HF}$ gas concentrations between $\sim 900$ and $1800 \mathrm{ppm}$ in the gas phase. This corresponds to HF solubilities in the Flibe that are $\sim 100-200$ times higher than expected in a fusion blanket. The autotitrator used $0.1 \mathrm{~N} \mathrm{NaOH}$ to maintain the $\mathrm{pH}$ constant while gas containing $\mathrm{HF}$ was bubbled through a stirred titration cell. The autotitrator and QMS yielded both consistent and complimentary results. The QMS directly measures concentration of $\mathrm{HF}$ in the effluent, while the autotitrator directly measures cumulative moles of HF that have been collected.

The reactor, shown in more detail in Fig. 11, was designed to provide a controlled reaction between $\mathrm{Be}$ and $\mathrm{HF}$ in the molten salt phase. The HF was introduced into the system via bubbling into the salt in a gas mixture that also contains $\mathrm{H}_{2}$ and $\mathrm{He}$. The $\mathrm{H}_{2}$ is intended to minimize the likelihood of $\mathrm{HF}$ reacting with metal components in the system hardware. The He is a carrier gas so that the total actual flow rate was about $300 \mathrm{~cm}^{3} / \mathrm{min}$ to minimize transport time to the QMS and titrator. A cylindrical beryllium rod, $0.76 \mathrm{~cm}$ in diameter and $3 \mathrm{~cm}$ in length was introduced into the 


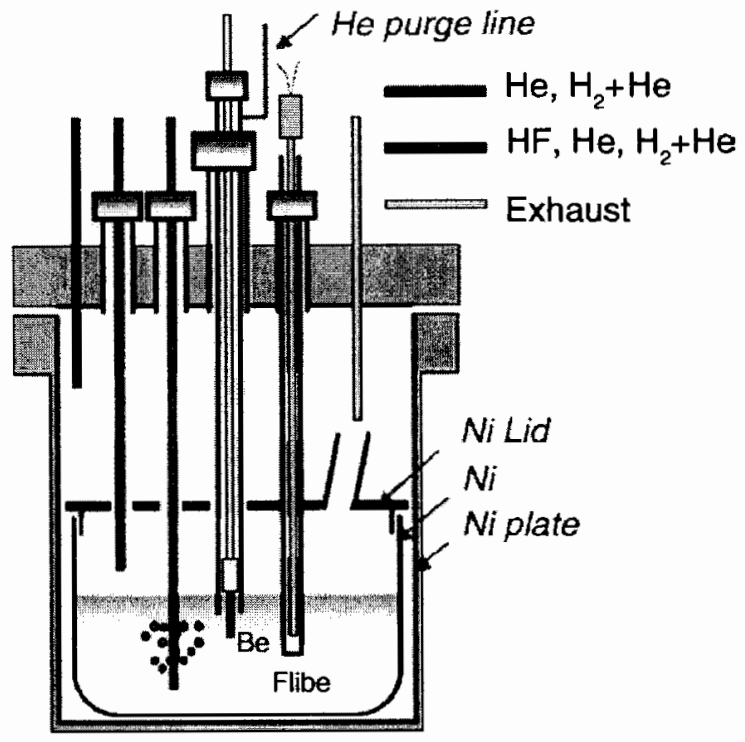

Fig. 11. Reactor for measuring redox behavior.

salt for a specified period of time. It is estimated that $1.9 \mathrm{~cm}$ of length was actually exposed to the salt, with the rest remaining within the mounting fixture. A nickel tube containing a slow flow of $\mathrm{He}(\sim 2-5 \mathrm{sccm})$ acted as a sheath to protect the Be specimen from contact with HF or salt (via capillary action) during times when it was not in the salt. All non-nickel metal surfaces inside of the reactor were spray coated with nickel to prevent HF from participating in corrosion-type side reactions.

Each experiment started with the $\mathrm{HF}-\mathrm{H}_{2}-\mathrm{He}$ feed gas bubbled into the salt with the Be specimen pulled out of the salt. Once the HF concentration in the effluent stabilized close to the expected level, the Be specimen was inserted into the salt. After 10-60 min, the Be was lifted out of the salt and into its protective housing while HF in the effluent was continually monitored for times ranging from several hours up to a few days. Once the HF concentration in the effluent had again stabilized, the next experiment was run by re-inserting the Be into the salt for a different duration. The same Be specimen was used for each experiment because the amount of material lost during each experiment was estimated to be very low. As shown in Fig. 12, the effluent HF concentration as measured by the QMS dropped rapidly usually within a matter of minutes after the Be was initially inserted into the salt. The slow recovery of the effluent $\mathrm{HF}$ concentration after the Be was removed is

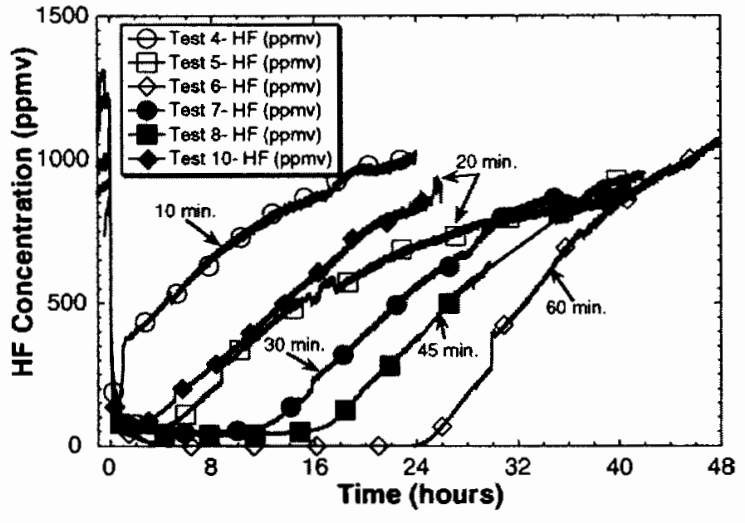

Fig. 12. HF concentration measured by QMS on the outlet of the REDOX experiment for several Be immersion times.

believed to be the result of continued reaction of $\mathrm{Be}$ dissolved in the salt with $\mathrm{HF}$ added by ongoing gas injection.

The autotitrator data from the redox experiments were used to estimate the amount of Be that dissolved into the salt for each experiment. The results of the analysis are shown in Fig. 13, where mole fraction of $\mathrm{Be}$ in the salt is plotted versus immersion time.

The linearity of the plot in Fig. 13 suggests a simple mass transfer mechanism with a high saturated concentration. This conclusion is supported by the results of our recent Be dissolution experiments [28] in which the saturated concentration of $\mathrm{Be}$ in the salt has been estimated to be $0.0022 \mathrm{~mol} / \mathrm{cm}^{3}$.

To further understand the interactions between molten Flibe and $\mathrm{Be}$, a series of Be dissolution experiments was performed in which a metallic Be rod was immersed in molten Flibe at $803 \mathrm{~K}$ under $\mathrm{He}$ atmosphere for $210 \mathrm{~h} \mathrm{[28]}$. The Be rod was significantly

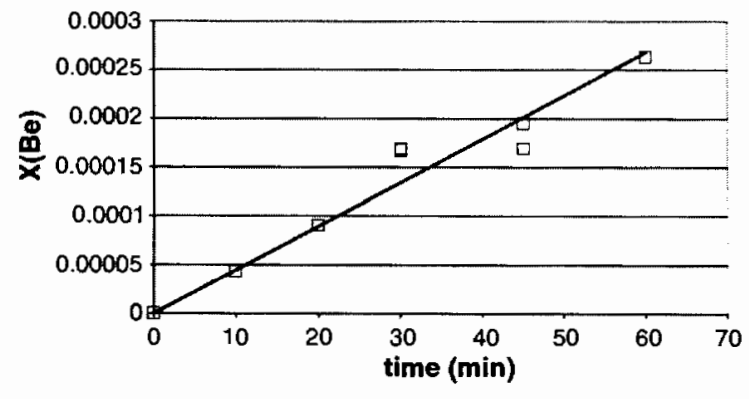

Fig. 13. Effect of immersion time on the initial mole fraction of $\mathrm{Be}$ in the sait. 

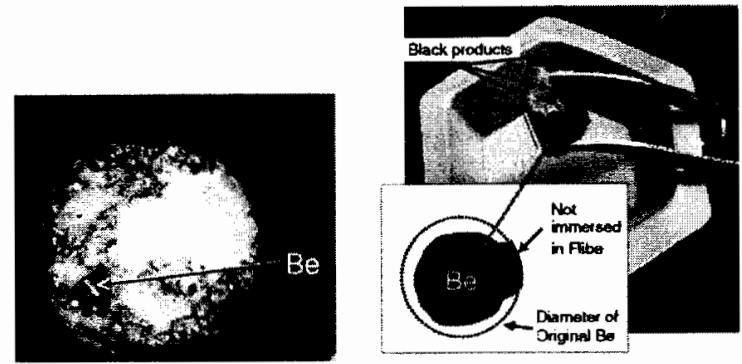

Fig. 14. Photographs of samples from Flibe/Be dissolution tests.

eroded during immersion in molten Flibe, and the Flibe changed from a clear crystal to a brownish-gray marblelike appearance (see Fig. 14). The concentration of $\mathrm{Be}^{0}$ in Flibe was evaluated by dissolving salt samples in acid solutions. This dissolution test is based on the reaction of $\mathrm{Be}^{0}$ with proton ions in the acid solutions to generate $\mathrm{H}_{2}$. Hydrogen gas was generated and collected from Flibe contacted with Be under flowing $\mathrm{He}$. The amounts of gas generated corresponded to mole fractions of $\left[\mathrm{Be}^{0}\right] /[\mathrm{Flibe}]$ ranging from $9.9 \times 10^{-4}$ to $7.6 \times 10^{-3}$. On the other hand, no $\mathrm{H}_{2}$ was generated from Flibe that was not exposed to $\mathrm{Be}$, or Flibe exposed to $\mathrm{Be}$ and then given significant $\mathrm{He}-\mathrm{H}_{2}-\mathrm{He}$ bubbling. These observations showed that $\mathrm{Be}$ does, indeed, dissolve in Flibe as $\mathrm{Be}^{0}$. The fact that no $\mathrm{Be}^{0}$ was detected after bubbling $\mathrm{H}_{2}-\mathrm{HF}-\mathrm{He}$ into the salt indicates that $\mathrm{Be}^{0}$ is an effective redox agent for reacting HF. Auger analysis of the deposits confirms this inference from these experiments.

Additional understanding about the behavior occurring in the salt can be obtained by converting the data in Fig. 13 to fractional conversion of HF (defined as one minus the ratio of the HF QMS data to the HF concentration being added to the pot). The results shown in Fig. 15 all illustrate similar behavior but differ in their time response because of the difference in Be exposure time in the salt (given in parentheses in the legend of Fig. 15). The fractional conversion of HF peaked above 0.9 for each run and then required as much as $60 \mathrm{~h}$ to return to zero. A simple first order kinetics model, shown as the curve fits in Fig. 15 and described in reference [29] appear to be reasonably representative of the data.

The integrated moles of HF reacted was used to estimate the mole fraction of $\mathrm{Be}$ in the salt $\left(x_{\mathrm{Be}}\right)$ as a function of time. In Fig. 16, the fractional conversion

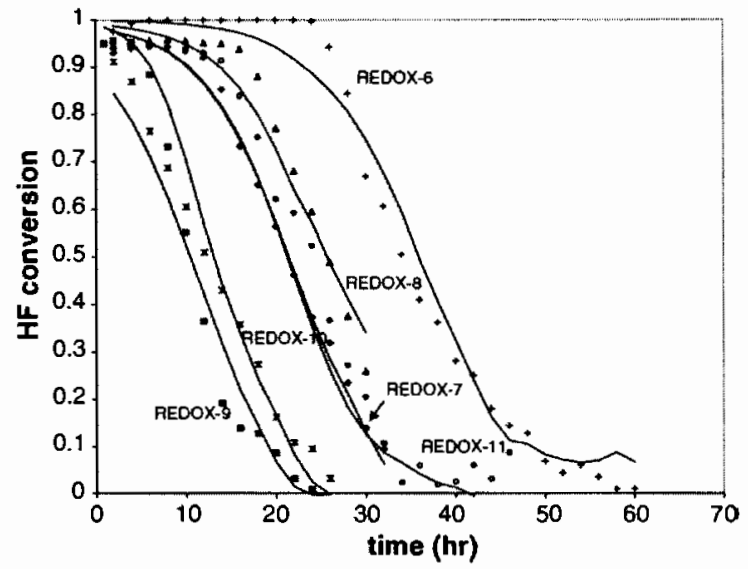

Fig. 15. HF conversion versus time for redox experiments (solid lines are kinetic model fits to the data).

of $\mathrm{HF}$ is plotted versus the time varying mole fraction of beryllium in the salt, $x_{\mathrm{Be}}$. The results show a remarkable similarity over a range of $\mathrm{Be}$ exposure times (Be mole fraction dissolved in the salt). Also shown in Fig. 16 is a single line that is based on the kinetics model developed in Ref. [29]. The results indicate that the model in this dimensionless form does a very good job of predicting the conversion of $\mathrm{HF}$ as a function of Be dissolved in the salt over a broad range of $\mathrm{Be}$ exposure times and $\mathrm{HF}$ gas concentrations between $\sim 900$ and $1800 \mathrm{ppm}$.

These experiments have indicated that Be solubility in the Flibe at $530^{\circ} \mathrm{C}$ is about $0.1 \mathrm{wt} \%\left(x_{\mathrm{Be}}=0.0036\right)$ [5]. At this level, the TF concentration in the salt

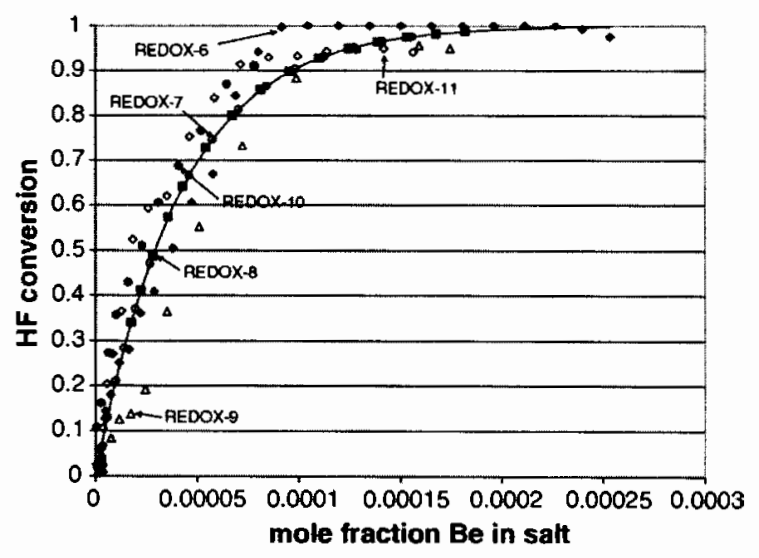

Fig. 16. HF conversion versus mole fraction of $\mathrm{Be}$ in the salt for all REDOX tests (solid line is kinetic model fit to data). 
could be maintained at a level well below $0.019 \mathrm{ppb}$. This is expected to keep the corrosion rate acceptably low.

Thus, our results to date have demonstrated the REDOX process in a laboratory scale experiment by using $\mathrm{Be}$ as the REDOX agent. The experiments used HF concentrations that were $\sim 100$ times higher than that expected in a fusion blanket. The kinetics of the REDOX process was rapid in converting $\mathrm{HF}$ to $\mathrm{H}_{2}$. Continued reaction of HF following removal of the $\mathrm{Be}$ from the Flibe indicates that dissolved $\mathrm{Be}$ is acting to reduce the HF. A simple kinetics model has been developed to predict the expected HF concentration as a function of $\mathrm{Be}$ dissolved in the salt. Future work includes improving the kinetics model to incorporate the uncertainty and impurity effects and performing additional experiments at lower $\mathrm{HF}$ concentrations $(\sim 100-250 \mathrm{ppm})$ that are closer to those expected in a fusion reactor. Measurement limitations prevent us from performing experiments at typical fusion blanket conditions. Our modeling will be used to extrapolate down to blanket conditions to make preliminary assessments of the use of $\mathrm{Be}$ as a redox agent in a fusion blanket. Following the lower concentration experiments, simple dip tests of fusion structural materials are planned with and without Be to demonstrate the reduction in corrosion with $\mathrm{Be}$ as a redox agent.

\section{Summary and conclusions}

This document presents an update on the Flibe experiments that have conducted under the US/Japan JUPITER-II collaboration. The experimental program has been focused on addressing the key feasibility issues associated with the use of Flibe. To date, data have been gathered on purification of Flibe, deuterium transport in non-REDOX controlled Flibe, and Flibe mobilization under accident conditions. Most importantly, our initial REDOX experiments have indicated that $\mathrm{Be}$ is a good redox agent to control $\mathrm{HF}$ and the kinetics at fairly high concentrations are rapid. In the final two years of the collaboration, experiments are planned to study tritium behavior in Flibe with and without REDOX control and to study reduction in the corrosion of fusion structural materials in the presence of $\mathrm{Be}$ as a REDOX agent.

\section{Acknowledgements}

The work was supported partially by U.S. Department of Energy Office of Fusion Energy Sciences, and by the Japan-US joint research program, JUPITERII, under DOE Idaho Operations Contract DE-AC0799ID13727.

\section{References}

[1] R.W. Moir, HYLIFE-II: a molten-salt inertial fusion energy power plant design-final report, Fusion Technol. 25 (January 1994).

[2] D.-K. Sze, M. Sawan, E.T. Cheng, Impact of transmutations in fusion environment on flibe chemistry, Fusion Technol. 39 (2) (March 2001) (Part 2).

[3] L. Cadwallader, G. Longhurst, Flibe use in fusion reactors: an initial safety assessment, INEEL/EXT-99-00331, May 1999.

[4] 10CFR850, Chronic Beryllium Disease Prevention Program, January 2001.

[5] H. Moriyama, Chemical behaviors of tritium formed in LjF-BeF 2 mixtures, J. Nucl. Mater. 148 (1987) 211-216.

[6] T. Terai, Tritium release from $\mathrm{Li}_{2} \mathrm{BeF}_{4}$ molten salt breeder under neutron irradiation at elevated temperature, Fusion Technol. 39 (2001) 768 .

[7] A. Suzuki, In-situ HT release behavior from molten $\mathrm{Li}_{2} \mathrm{BeF}_{4}$ salt, Fusion Eng. Des. 39-40 (1998) 781-785.

[8] A. Suzuki, Change of tritium species in $\mathrm{Li}_{2} \mathrm{BeF}_{4}$ molten salt breeder under neutron irradiation at elevated temperature, $J$. Nucl. Mater. 258-263 (1998) 519-524.

[9] A. Suzuki, Change of tritium species in $\mathrm{Li}_{2} \mathrm{BeF}_{4}$ molten salt breeder under neutron irradiation at elevated temperature, Fusion Technol. 34 (1998) 526-530.

[10] T. Terai, In-situ tritium release experiment from molten $\mathrm{Li}_{2} \mathrm{BeF}_{4}$ salt under neutron irradiation at elevated temperature (INTREXFLIBE), Fusion Technol. 30 (1996) 911.

[11] J. Oishi, Tritium recovery from molten $\mathrm{LiF}-\mathrm{BeF}_{2}$ salt, Fusion Eng. Des. 8 (1989) 317

[12] H. Moriyama, The effect of fusion neutron irradiation on tritium recovery from lithium salts, J. Nucl. Mater. 161 (1989) 197.

[13] A.P. Malinauskas, The solubilities of hydrogen, deuterium, and helium in molten $\mathrm{Li}_{2} \mathrm{BeF}_{4}$, Ind. Eng. Chem. Fundam. 13 (3) (1974) 242.

[14] P.E. Field, J.H. Shaffer, The solubilities of hydrogen fluoride and deuterium fluoride in molten fluorides, J. Phys. Chem. 71 (10) (1967) 3218 .

[15] R.A. Anderl, Deuterium/tritium behavior in Flibe and Flibefacing materials, J. Nucl. Mater. 329-333 (2004) 1327-1331.

[16] S. Fukada, Initial studies of tritium behavior in Flibe and Flibefacing materials, Fusion Eng. Des. 61-62 (2002) 78.

[17] S. Fukada, Flibe- $D_{2}$ permeation experiments and analysis, Fusion Sci. Technol. 44 (2003) 410.

[18] S. Cantor, Physical properties of molten-salt reactor fuel, coolant and flush salts, ORNL-TM-2316, August 1968. 
[19] T. Ohmichi, J. Phys. Chem. 80 (1976) 1628.

[20] G.R. Smolik, Mobilization measurements from Flibe under argon and air flow, J. Nucl. Mater. 329-333 (2004) 1322-1326.

[21] S. Cantor, D.S. Hsu, W.T. Ward, Vapor pressures of fluoride salts, in: W.R., Grimes (ed.), Reactor Chemistry Division Annual Progress Report, ORNL-3913, ORNL, 1966, pp. 24-26.

[22] D.R. Olander, Equilibrium pressures over BeF2/LiF (Flibe) molten mixtures, Fusion Sci. Technol. 41 (2002) 141-150.

[23] M.R. Zaghloul, D.K. Sze, A.R. Raffray, Thermo-physical properties and equilibrium vapor-composition of lithium fluorideberyllium fluoride (2LiF/BeF2) molten salt, Fusion Sci. Technol. 44 (2003) 344.

[24] A. Büchler, J.L. Stauffer, Vaporization in the lithium fluoride-beryllium fluoride system, in: Symposium on Thermodynamics of Nuclear Materials, International Atomic Energy Agency, 1966, pp. 271-290.

[25] B.J. Merrill, Safety assessment of two advanced ferritic steel molten salt blanket design concepts, Fusion Eng. Des. 72 (1-3) (2004) 277-306
[26] K.A. Sense, C.A. Alexander, R.E. Bowman, R.B. Filbert Jr., Vapor pressure and derived information of the sodium fluoridezirconium fluoride system, J. Phys. Chem. 61 (1957) 337344.

[27] T. Terai, A. Suzuki, S. Tanaka, Tritium release from $\mathrm{Li}_{2} \mathrm{BeF}_{4}$ molten salt breeder under neutron irradiation at elevated temperature, Fusion Technol. 39 (March 2001) 768 772.

[28] M. Hara, Y. Hatano, M.F. Simpson, G.R. Smolik, J.P. Sharpe, Y. Oya, K. Okuno, M. Nishikawa, T. Terai, S. Tanaka, R.A. Anderl, D.A. Petti, D.-K. Sze, Interactions between molten Flibe and metallic Be, Fusion Eng. Des. 81 (2006) 561566.

[29] M.F. Simpson, G.R. Smolik, J.P. Sharpe, R.A. Anderl, D.A. Petti, Y. Hatano, M. Hara, Y. Oya, S. Tanaka, T. Terai, D.-K. Sze, Quantitative measurement of beryllium-controlled redox of hydrogen fluoride in molten Flibe, Fusion Eng. Des. 81 (2006) 541-547 